\section{Discover more about dental implantology}

For any delegates at Dental Showcase with a growing or existing interest in dental implantology, there were plenty of sources of information and advice.

Among the exhibitions stands was the Association of Dental Implantology (ADI) and the team demonstrated just why it remains such a popular organisation in modern dentistry.

As demand increases and the field expands, there are many different ways for dentists and their teams to get involved with dental implantology. Many visitors to the ADI stand were keen to find out about the pathways available to them, with others looking to take their skills to the next level through education, supported by the ADI.

Whatever your past experience with dental implants, the ADI provides a range of resources to help you on your way.

If you missed the ADI at Dental Showcase, information on the organisation and the many benefits available to members is readily available on the website - visit today.

For more information about the ADI, or to join, visit www.adi.org.uk/membership.

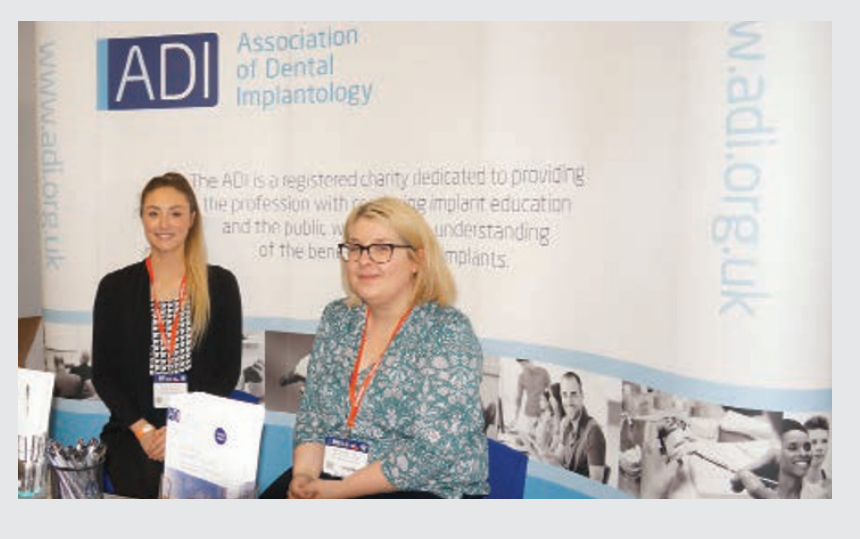

\section{A successful launch for an innovative system}

MyCrown - a new, fully integrated CAD CAM and chair side milling system for restorations, launched at the BDIA Dental Showcase and impressed delegates with its simplicity and speed.

MyCrown's acquisition unit has both 2D and 3D capabilities and removes the need for traditional impressions. This enables practitioners to produce everyday restorations chairside, including crowns, inlays, onlays, veneers and up to three unit bridges.

Delegates were able to sit, scan, design and mill the restorations at the My Crown stand allowing them to see the finished product first hand. Dental professionals were particularly impressed with the intuitive, touchscreen technology and the convenience of a fully guided workflow system to streamline the creation of restorations.

MyCrown is a system that provides open STL files. It is compatible with the majority of ceramic blocks and doesn't restrict you to a single material.

If you missed out on the chance to meet the team behind MyCrown and see this state-of-the-art system for yourself, why not visit the website to find out more?

For more information, visit www.my-crown.co.uk or call 03339873007.

\section{A global launch in Birmingham}

The CALCIVIS imaging system was unveiled in a global launch at this year's BDIA Dental Showcase, with practitioners able to see the innovative system for themselves and learn more through a series of talks held throughout the event.

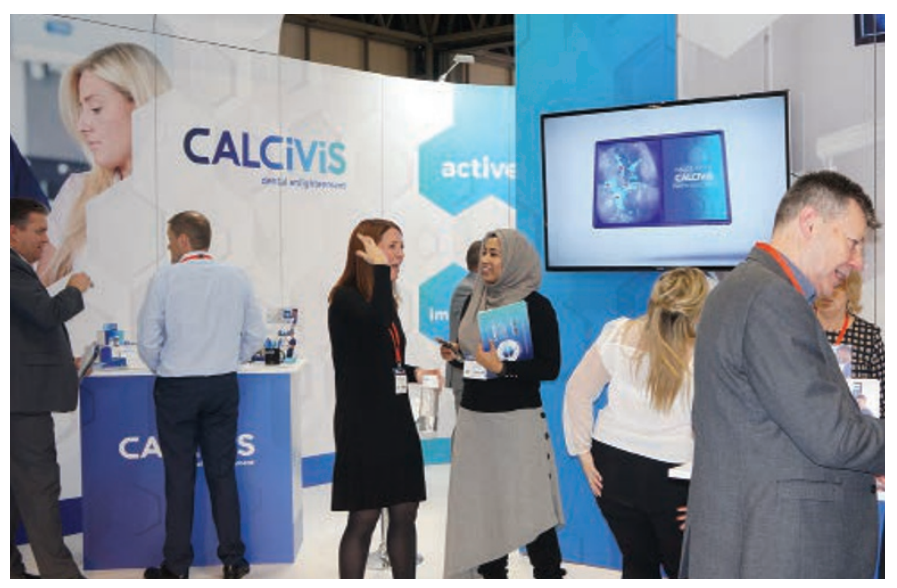

Lectures on the exclusive system - which uses bioluminescence to help identify early active demineralisation - were delivered by independent clinicians, who explained the benefits of CALCIVIS and how their preventive practice is set to improve as a result. The 'demin-map' that is produced using CALCIVIS' unique dental biologic can be used to show patients where future problems could arise, helping engage patients in active preventive measures at a time when simple steps can be highly effective.

CALCIVIS offered the first $100 \mathrm{UK}$ practices who committed to trying the system a VIP starter kit and induction training at a saving of more than $40 \%$.

A truly innovative product for preventive dentistry, the CALCIVIS imaging system represents a step into the future.

To register for the VIP offer visit www.CALCIVIS.com.

\section{Best on show}

Year upon year the BDIA Dental Showcase grants dentists the opportunity to discover the very latest and greatest in dental technology and patient care solutions.

Amongst those that grabbed the attention of delegates was the ClearSmile Laboratory, a team of leading technical experts dedicated to the planning and production of the ClearSmile Inman Aligner, ClearSmile Aligner, ClearSmile Brace, and ClearSmile Discreet.

Working in collaboration with the IAS Academy's respected team of GDPs, the team of leading technical experts ensure that all appliances are made to exacting standards to provide an orthodontic solution that is safe and effective.

If you missed ClearSmile Laboratory at the Showcase, don't worry - simply get in touch with the team today and they'll be able to help you with your query. Alternatively, go online to discover more about the appliances and upcoming courses.

For more information about ClearSmile Laboratory visit www. iasortho.com or email enquiries@iasortho.com. 